\title{
ONTOLOGÍA Y RAZÓN TRINITARIA
}

\author{
Alessandro Clemenzia \\ Instituto Universitario Sophia - Loppiano, Italia
}

\section{RESUMEN / ABSTRACT}

La ontología trinitaria indica el pasaje de un ser in se, que se autoconstruye y se auto-realiza, a uno que es desde el momento en que se desplaza el propio baricentro existencial del in se al "para" y "en" el otro. Esta dinámica, reveladora del ser Dios de Dios, se manifiesta de un modo fundamental en el evento pascual e imprime una novedad decisiva, mediante la introducción de lo negativo (no-ser), en las estructuras mismas de pensamiento.

The Trinity ontology shows a being in se, which is built and made by itself, a being that is since the moment in which is moved from in se to for and in the other. This dynamic, which reveals the God-being-God, is showed fundamentally in the Easter and it prints a decisive novelty, by means of the negative (non-being) inclusion in the structures of thought.

"Ontología y razón trinitaria". Éste es el título que me ha sido marcado como punto de partida, punto de llegada y horizonte dentro del cual moverme en esta investigación.

Antes de exponer los puntos más relevantes de la misma, quisiera introducir sintéticamente los ejes que serán aquí presentados. En primer lugar, llevaremos a cabo una "explicatio terminorum", tratando de hacer ver qué se entiende concretamente por "ontología trinitaria”, y cuál es el recorrido que ésta ha ido siguiendo a lo largo de la Tradición de la Iglesia, aun habiendo asumido en el curso de los siglos, diversas denominaciones: de hecho, no siempre un 
nombre nuevo introduce en la lengua un nuevo significado o una nueva operación conceptual. En un segundo momento, propondré una posible lectura teológica de cómo Dios mismo, en Cristo y en el Espíritu, se ha revelado; una lectura que sirva de apoyo para captar el significado de la palabra fundamental del título de esta conferencia: "trinitaria". En un tercer punto, veremos cómo esta lógica divina, o mejor, teo-lógica, llega a fraguar el ritmo mismo del pensar humano. En otras palabras, trataremos de verificar si es posible que exista un inteligir humano susceptible de ser informado por la misma lógica trinitaria. Y, a partir de aquí, serán apuntados algunos elementos conclusivos.

Pasemos, por tanto, al primer punto: una explicación de los términos en cuestión.

\section{LA "ONTOLOGIA TRINITARIA"}

¿Qué entendemos por “ontología trinitaria”? No se puede pasar por alto tal pregunta, es más, precisamente porque esta locución es utilizada de diversos modos, se nos impone la necesidad de llevar a cabo una clarificación terminológica". La "ontología" tiene como referencia el sentido y la verdad que habitan todo aquello que "es", más allá de la funcionalidad que le pudiera ser propia². "Trinitaria", por el contrario, precisamente porque no actúa como sustantivo, sino como adjetivo, ejerce, en un cierto sentido, la calificación de lo que se está hablando (en nuestro caso, de la ontologia). "Trinitaria”,

\footnotetext{
Para profundizar de un modo sintético esta cuestión, cf. P. Coda, "Trinità", in J.-Y. Lacoste, Dizionario critico di Teologia, ed. it. a cura di P. Coda, Borla-Città Nuova, Roma 2005, pp. 1388-1416; L. Žák, Verso un'ontologia trinitaria, in P. Coda - L. Žák (edd.), Abitando la Trinità. Per un rinnovamento dell'ontologia, Città Nuova, Roma 1998, pp. 5-18; Id., "Unità di Dio: quaestio princeps dell'ontologia trinitaria", in Path 11 (2012/1), pp. 439-464.

2 Escribe Coda en este sentido: "In termine ontologia, carico di una lunga storia che inizia in Occidente agli albori della filosofia greca e giunge sino ad Heidegger e oltre, indica qualcosa d'estremamente semplice e decisivo a un tempo: la conoscenza del lógos dell'essente, del senso, della verità di ciò che è" (P. Coda, "Trinità", cit., p. 1412). Para una profundización sobre la historia de la ontología, seguido de referencias bibliográficas actualizadas, cf. Storia dell'ontologia, a cura di M. Ferraris, Bompiani, Milano 2009².
} 
en particular, alude a la perspectiva desde la que se observa, y, por ello, al lugar desde el que se mira una particular realidad. El evento de Jesús determina, en efecto, sobre el plano comunitario-eclesial y sobre el personal-antropológico, un cambio radical de lugar y de perspectiva. Y todo ello goza de una importancia imprescindible para "hacer" teología: Dios, de hecho, es el objeto (sujeto) de la reflexión teológica. Pero no se limita a esto: Él es además el espacio en el que el hombre ha sido llamado a introducirse, y por el cual mirar (y, por ello, interpretar) todo aquello que $\mathrm{es}^{3}$.

La expresión "ontología trinitaria" ha salido a la palestra en un ensayo del teólogo y filósofo Klaus Hammerle de 1976, titulado "Thesen zu einer trinitarischen Ontologie" ("Tesis de Ontología Trinitaria"), escrito y publicado en honor del septuagésimo cumpleaños de Hans Urs von Balthasar. Se trata éste de un trabajo reconocido como una de las expresiones más altas de la reflexión post-conciliar. Aunque Hammerle sea responsable del auge de esta expresión, no se puede afirmar que él haya sido su inventor: presente ya en una obra de Theodor Haecker (publicada en 1934$)^{5}$, la trinitarische Ontologie ha sido objeto de estudio de Clemens Kaliba ${ }^{6}$ y de Ernest Davey ${ }^{7}$, a partir de los años cincuenta.

3 Como ha afirmado el teólogo italiano Piero Coda: "È chiaro, dunque, che Gesù, insieme a chi lo segue, si trova a inaugurare nella storia, per dono ("grazia", nel linguaggio neotestamentario), una nuova situazione dell'essere e un luogo nuovo da cui guardare, interpretare e vivere l'essere di ciò che è: Dio, gli uomini, la storia, il cosmo. Non si tratta soltanto di un fatto religioso e spirituale, e neppure soltanto di un fatto etico: ma, appunto, di una situazione ontologica. Nell'evento di Gesù -continúa Coda- sono poste così le premesse ontologiche ed esistenziali per un'originale visione di tutta la realtà, vista, amata, vissuta e capita nella luce dischiusa dal luogo in cui Gesù introduce l'umanità: il seno del Padre, la Trinità, dove l'essere si apre e si comunica in chiarezza evidente per ciò che è - agápe" (P. Coda, "L'ontologia trinitaria: che cos'è?", in Sophia IV (2012/2), pp. 159-170, qui p. 162). El mismo autor, con vistas a una profundización fenomenológica y ontológica del concepto de ágape, reenvía a su texto L'agape come grazia e libertà. Alla radice della teologia e prassi dei cristiani, Città Nuova, Roma 1994.

4 Cf. K. Hemmerle, Thesen zu einer trinitarischen Ontologie, Johannes Verlag, Einsiedeln 1976, tr. it. Tesi di ontologia trinitaria, Città Nuova, Roma $1996^{2}$.

5 T. Haecker, Schöpfer und Schöpfung, Hegner, Leipzig 1934.

6 C. Kaliba, Die Welt als Gleichnis des dreieinigen Gottes. Entwurf zu einer trinitarischen Ontologie, Otto Müller Verlag, Salzburg 1952.

7 J.E. Davey, "Lines of Approach to a Trinitarian Ontology", in The Hibbert Journal 55 (1956), pp. 223-232. 
Desde el año 1970 en adelante, esta nueva expresión, con la consiguiente nueva configuración, se ha difundido rápidamente en los diversos ambientes filosóficos y teológicos sobrepasando las fronteras de Alemania. En Italia, por ejemplo, la intuición de esta nueva ontología, releída a la luz de la revelación de Dios Trinidad, ha sido llevada a cabo de un modo particular por Giuseppe Maria Zanghi y Piero Coda; sobre todo por este último, quien además de profundizar científicamente el tema, ha hecho explícito su estatuto epistemológico y ha reseñado las implicaciones del mismo para la teología y la filosofia, contribuyendo así al nacimiento de un departamento que tiene como especialidad propia la ontología trinitaria, en el nuevo Instituto Universitario Sophia (cuya sede se encuentra en Loppiano, cerca de Florencia).

La gran cuestión teológica, planteada por los autores mencionados, orienta su reflexión a partir de la unidad de Dios. Se podría así resumir este punto nodal en la siguiente pregunta: ¿Cómo concebir la unidad de Dios a la luz de su trinidad? Tal interrogación gira entorno a la comprensión de la unidad entendida trinitariamente y no de la trinidad a partir de la unidad divina. Esta operación requiere poder pensar la unidad y la trinidad de Dios en su fecunda interrelación y compenetración ${ }^{8}$.

La "ontología trinitaria", aun habiéndose desarrollado en la segunda mitad del siglo XX, posee una perspectiva lógica $\mathrm{y}$ teorética que encuentra en los grandes pensadores de la tradición un vasto fundamento. Bástenos pensar, en este sentido, en figuras fundadoras de la reflexión teológica, como Agustín de Hipona, el cual ha concentrado su atención en el paso de la sustancia a la relación, del ser-en-sí al ser-con/para-el-otro. Para el obispo de Hipona, el concepto de unidad entendido en el plano antropológico y eclesiológico encuentra su criterio hermenéutico en la unidad misma de Dios (entendida no ya sólo en el plano sustancial, sino sobre todo a la luz de la relación). Sin detenerme más en Agustín o en otros eminentes representantes del pensamiento cristiano (por ejemplo, Tomás de Aquino, Dionisio Areopagita, Buenaventura,...

8 Cf. P. Coda, "Ripensare l'unità di Dio nella luce della rivelazione. Un percorso metodologico", in Path 11 (2012/1), pp. 279-299. 
que han ofrecido criterios interpretativos fundamentales a la presente cuestión teológica) ${ }^{9}$, es interesante ver cómo, en las raíces mismas de la ontología trinitaria, han jugado un papel central, a simple vista sorprendente, también otros autores: Hegel y Rosmini ${ }^{10}$. Más allá de aquellos que han forjado la reflexión filosófica y teológica occidental, en el interior de la Ortodoxia, pueden hallarse de igual modo defensores de la ontología trinitaria; piénsese, por ejemplo, en P.A. Florenskij y S.N. Bulgakov ${ }^{11}$.

Piero Coda, a quien quisiera citar para ofrecer una precisa indicación sobre el significado de ontología trinitaria, afirma:

El término "ontología trinitaria" puede ser tomado en dos sentidos: uno más amplio y otro, más estricto. En sentido amplio, ontología trinitaria designa cada interpretación de la realidad que -explícita o implícitamentearranque del lugar al que el evento de Cristo nos ha llevado. (...) En este sentido -y esto es sin duda un tema que debe ser profundizado-, una ontología trinitaria puede constituir el horizonte interpretativo de referencia,

9 Pienso en verdad que la contribución que estos autores han ofrecido a la ontología trinitaria vaya más allá de su inicial deseo de querer contemplar "el reflejo del misterio del Dios Trinidad en la creación" (L. Žák, "Premessa: verso un’ontologia trinitaria", in P. Coda e L. Žák (edd.), Abitando la Trinità. Per un rinnovamento dell'ontologia, Città Nuova, Roma 1998, pp. 5-25, aquí p. 5).

10 Un primer trabajo científico sobre la contribución de Hegel a la actual reflexión trinitaria es P. Coda, Il negativo e la Trinità. Ipotesi su Hegel, Città Nuova, Roma 1987. Numerosas, en los últimos años, han sido las investigaciones sobre Antonio Rosmini, es suficiente mencionar B. Forte, "Il Divino nell'uomo. Antonio Rosmini", in Id., Sui sentieri dell'Uno. Saggi di storia della teologia, Ed. Paoline, Cinisello Balsamo (Mi) 1992, 219-239; P. Coda, "La Trinità delle Persone come attuazione agapica dell'essere uno. Il contributo di A. Rosmini per un rinnovamento della teo-onto-logia trinitaria", in K.-H. Menke, A. Staglianò, Credere pensando. Domande della teologia contemporanea nell'orizzonte del pensiero di Antonio Rosmini, pp. 251-272; G. Lorizio, "Ricerche della verità e "metafisica della carità" nel pensiero di Antonio Rosmini", in K.-H. Menke, A. Staglianò, Credere pensando, cit., 461-486.

11 En estos últimos decenios es sobre todo la teología de Bulgakov la que representa un punto sin retorno para la teologia trinitaria. Para una profundización sistemática, cf. P. Coda, L'altro di Dio. Rivelazione e kenosi in Sergej Bulgakov, Città Nuova, Roma 1998; Id., Sergej Bulgakov, Morcelliana, Brescia 2003; Id., "Cristologia della kenosi e della gloria. La sintesi sociologica di S. Bulgakov", in S.N. Bulgakov, L'Agnello di Dio. Il Mistero del Verbo incarnato, Città Nuova, Roma 1990, pp. 11-35; G. Lingua, Kenosis di Dio e santità della materia. La sofiologia di S.N. Bulgakov, Edizioni Scientifiche Italiane, Napoli 2000. 
libre y plural, de cada interpretación particular de la realidad llevada a cabo por saberes distintos (...) Existe además un significado más estricto y epistemológicamente más preciso de "ontología trinitaria", según el cual esta expresión se refiere a aquella interpretación especifica del ser en cuanto ser que brota de la toma de conciencia formalmente instituida del lugar al que Jesús nos ha llevado teniendo en cuenta su relevancia propiamente ontológica ${ }^{12}$.

A la luz de cuanto se ha afirmado, "trinitaria", en relación con la ontología, no es ni el sujeto (nominativo), ni el objeto (acusativo), sino el espacio (caso ablativo) en el que el hombre puede y debe injertarse para captar la realidad misma en la que habita. Es necesario ser "en Dios" (como estando en un lugar), para ver "desde Dios" (como movido desde un lugar) lo humano: es ésta una mirada teo-lógica.

Precisamente porque el objeto de la teologia, como acaba de verse, no es sólo Dios (el cual es siempre el sujeto de la teología) sino la misma realidad humana, el evento cristiano tiene por ello una fecundidad no sólo religiosa, sino además cultural y ontológica: lee e interpreta todo trinitariamente. Por este motivo, en la ontologia trinitaria encuentran su hogar disciplinas tan distantes entre sí, aunque no "separadas", como la teología, la filosofia, la epistemología y la lógica.

Joseph Ratzinger, en su obra Introducción al Cristianismo, teniendo como referencia sobre todo el De Trinitate de Agustín, ha puesto de relieve la fecundidad ontológica de la reflexión trinitaria sobre la relación; con este propósito, ha escrito:

En esas palabras se oculta la imagen revolucionaria del mundo: el omnimodo dominio del pensar sustancial queda destruido; la relación se concibe como una forma primigenia de lo real, del mismo rango que la sustancia; con esto se nos revela un nuevo plano del ser. Probablemente pueda afirmarse que el cometido del pensar filosófico originado por estas observaciones no se ha realizado todavia lo suficiente; el pensar moderno depende en gran parte de las posibilidades aqui mencionadas, sin ellas no podría siquiera concebirse ${ }^{13}$.

12 P. Coda, "L'ontologia trinitaria: che cos'è?", cit., p. 165.

13 J. Ratzinger, Einführung in das Christentum. Vorlesung über das Apostolische Glaubensbekenntnis, Kösel Verlag, München 1968, tr. it. Introduzione al Cristianesimo, Queriniana, Brescia 19796 , 140-141. A propósito esta consideración, ha 
A partir de esta cita del teólogo Ratzinger es posible comprender cómo la Trinidad, a través de la reflexión sobre el ser, no es sólo una nueva propuesta argumentativa (que ha sido llamada "pensamiento objetivante"), sino que ofrece además un nuevo ritmo al pensamiento mismo.

El teólogo Lubomir Žák ha escrito recientemente un artículo acerca de la cuestión de la unidad de Dios en el que explica cómo no es posible hablar de un único modelo, o de una única propuesta, de ontología trinitaria. En este sentido, escribe:

El hecho de que exista no sólo más de una propuesta, sino también más de un modelo de ontología trinitaria (y, por ello, diferentes "ontologías trinitarias") depende, por una parte, de la diferencia entre las filosofias de partida $y$ de referencia de los primeros y de los actuales propugnadores de la "nueva ontología"; por otra parte, de una elección no del todo homogénea de lo que debería ser el objeto formal y material de una ontología trinitaria $y$, a la vez, de las áreas de aplicación de ésta última ${ }^{14}$.

La ontología trinitaria, en verdad, por cuanto debe reflejar la realidad más profunda que expresa, no puede presentarse

comentado Piero Coda: «Da notare, nell'affermazione di Ratzinger, una precisa sottolineatura: l'intuizione agostiniana dell'essere di Dio (Padre, Figlio e Spirito Santo) come relazione non costituisce una novità soltanto dal punto di vista oggettivo (in riferimento all'oggetto del pensiero: dal primato assoluto della sostanza all'equipollenza della relazione), ma anche dal punto di vista soggettivo (in riferimento al soggetto che pensa: dal pensiero "oggettivante" al pensiero come relazione viva)" (P. Coda, Sul luogo della Trinità. Rileggendo il De Trinitate di Agostino, Città Nuova, Roma 2008, p. 24, nota 13).

14 L. Žák, "Unità di Dio: quaestio princeps dell'ontologia trinitaria", cit., p. 442. Es interesante cuanto el autor subraya en la nota: "Questa scelta si concretizza in almeno tre tipi di impostazione metodologica e tematica: quello che ritiene essenziale per l'ontologia trinitaria uno studio sull'impronta trinitaria nell'essere della realtà creata, in particolare nell'essere uomo come persona: imago trinitatis; quello che primariamente punta sulla questione dell'essere unitrino di Dio quale argomento fondativo del pensiero ontologico-trinitario; infine quello che si concentra sullo studio delle dinamiche trinitarie della società. Se il primo tipo di impostazione connette l'ontologia trinitaria strettamente, e in alcuni esclusivamente, con la cosmologia e l'antropologia; se il secondo ne fa l'anima della riflessione speculativa sulla Trinità immanente e, tramite e a partire da essa, su tutto ciò che viene alla luce grazie all'opera della Trinità economica; il terzo gruppo è interessato a esaminare in modo particolare la possibilità di ripensare sull'orizzonte dell'ontologia trinitaria i temi di sociologia, di politologia o di economia" (Ibid., p. 442, nota 10). 
reductible a un único modelo de reflexión, con categorías unívocas, dentro de un sistema conceptual cerrado, definitivo y excluyente; de lo contrario ¡dejaría de ser lo que es! En efecto, sólo puede ser "ontología trinitaria" al entrar en relación con el otro, y así, con las diversas concepciones del mundo, y en este preciso encuentro con el otro, recupera con una novedad permanente su identidad abierta, no como escuela de pensamiento (estructuralmente homologado), sino como horizonte interpretativo, siempre dialógico.

Tras haber ofrecido algunas sugerencias sobre el significado de "ontología trinitaria", es posible ahora dirigir la atención hacia una profundización escriturística y teológica del evento que ha revelado el conocimiento de Dios: el evento del abandono. Jesús en la entrega total de sí, clave irrenunciable de una ontología trinitaria, es el lugar donde el ser-con/para-el-otro ha encontrado no sólo el modelo ejemplar, sino el camino y la puerta de acceso al misterio de Dios.

\section{PARA UNA LECTURA TRINITARIA DEL EVENTO PASCUAL}

Sin excluir las diversas interpretaciones teológicas de la crucifixión a la luz del misterio trinitario, la que aquí se propone es una lectura del evento pascual como acto del Padre, del Hijo y del Espíritu Santo, sobre la estela de la contribución de Piero Coda, que, a mi forma de ver, expresa claramente un modo trinitario de leer el evento pascual ${ }^{15}$.

En la reflexión teológica de la Iglesia a lo largo de los siglos, el misterio pascual ha representado siempre un papel central; y sin embargo, sólo a partir de la segunda mitad del siglo pasado, éste ha adquirido su plena centralidad, no sólo por su referencia soteriológica (es decir, pro nobis et propter nostram salutem), sino sobre todo por su carácter revelador: en él, se muestra el rostro de Dios, de una forma tan nueva que reinterpreta y otorga un nuevo significado a todo lo que de Él se había expresado (en teología, es el final el que explica el principio, el tèlos explica la arjé, no al revés). En aquel evento se nos re-vela, es más se nos des-vela, el ser mismo de Dios, y por ello su carácter trinitario.

15 Cf. P. Coda, Dalla Trinità. L'avvento di Dio tra storia e profezia, Città Nuova, Roma 2011, pp. 262-286. 
Naturalmente en el centro de la escena, como si el Gólgota pudiese convertirse por un momento en una escena teatral de la más bella representación teo-dramática, el protagonista principal es Jesús, el Nazareno, que vive (casi sufre) tal circunstancia. Él, de hecho, es crucificado fuera de los muros de la ciudad (cf. Mt 27,32; Heb 13, 12-13), subrayándose así cómo el evento acontece fuera del lugar de la alianza entre Dios y su pueblo. Y sin embargo, en toda la escena, lo que más resalta del Hijo es Su continua e ininterrumpida relación con el Padre, que alcanza su punto culminante en aquel grito de abandono, recogido en los evangelios de Marcos y de Mateo: "Dios mío, Dios mío, ¿por qué me has abandonado?". Es ésta con seguridad una cita del Salmo veintidós, pero, al mismo tiempo, son palabras que van mucho más allá de la referencia veterotestamentaria, reinterpretándola de hecho (precisamente porque, como se ha advertido ya, es el tèlos el que explica la arjé).

Tal grito, que irrumpe en el silencio del drama circunstancial, es la denuncia de quien, después de haber cumplido todo en relación con Alguien, experimenta, en aquel escenario de dolor y de muerte, la extrema pasividad y la total ausencia de Aquél. El Abba, Aquel que representaba para el Hijo el sentido de todo lo que sucedia, estaba ausente, o al menos, su presencia se expresaba paradójica y antinómicamente en aquella ausencia. Él "no" interviene, "no" habla, "no" se comunica más, y es precisamente la dureza de ese "no" lo que el Hijo experimenta. Es como si la relación del Padre con el Hijo se expresase con aquel "no", como si la presencia del Padre adquiriese la forma de aquel "no": sin embargo, precisamente alli, Dios, paradójicamente, desvela su paternidad; es una ausencia que le sirve al Hijo para poder expresar profundamente su libertad de Hijo. Escribe P. Coda a este respecto:

¿acaso no se manifiesta, precisamente de esta forma, la identidad última de aquella paternidad no paternalista del Abba en su relación con Jesús, que caracteriza su ministerio? (...) El ocultamiento y el silencio de Dios, en la cruz, su "abandonar" a Jesús en la prueba atroz del sentirse olvidado, dejado solo, hasta rechazado, son paradójicamente el sentido más auténtico de su ser Abba en su relación con el Hijo ${ }^{16}$.

16 Cf. P. Coda, Dalla Trinità, cit., p. 271. 
El abandono es así el culmen del que el Hijo tiene experiencia en la percepción y en la asunción de la retirada del Padre; y como el Padre en relación con el Hijo se ha expresado en el "no", así el Hijo ha debido sintonizar su filiación con esta nueva forma de paternidad. Jesús se re-abandona, con extrema totalidad y radicalidad, a Aquel que se hace presente en la forma de desgarradora ausencia. Aquí se puede comprender la profundidad de aquel grito de abandono; afirma Coda: "el abandono, en otros términos, expresa una radical dimensión de pasividad (Jesús es abandonado por el Padre) pero al mismo tiempo una proporcional actividad (Jesús se abandona, esto es, se confia al Padre) ${ }^{17}$.

El "no", desde este punto de vista, por ser el modo como el Padre y el Hijo se relacionan entre sí, es señal de la relación recíproca y asimétrica entre los Dos (es la forma, en otras palabras, de la paternidad y de la filiación). Y es, sobre todo en el evangelio de Lucas, en donde aparece expresamente esta dinámica filial de la entrega, en la que Jesús, volviéndose a abandonar, representa el signo más evidente de cuanto significa realmente la fe.

Siendo el evento pascual la manifestación plena del ser-Dios de Dios, más allá del Padre y del Hijo, se hace entonces necesario recuperar además el papel del "tertio incluso": el Espíritu Santo. Se trata de una presencia muy especial: es el único que no se ha presentado jamás a través del "Yo soy" (como fórmula de revelación divina en el Antiguo y en el Nuevo Testamento), ni ha hablado nunca de sí mismo. Son precisamente estas características las que hacen emerger su especificidad personal: su ser, en el ser relación; todo cual significa que el Pneuma está presente, desde el momento en que Él mismo reenvía a otro distinto-de-Sí. Y esto no es dificil de imaginar: si yo refiriese el amor entre dos personas, la atención del interlocutor estaría dirigida sobre dos sujetos que se aman, no sobre su ligamen, del que estoy hablando. La especificidad del amor es precisamente la de hacerse presente desplazando la atención desde sí hacia los otros.

17 Cf. J. Gnilka, Marco, Cittadella, Assisi 1987, p. 890, Cf. P. Coda, Dalla Trinità, cit., p. 275. 
En el evento pascual, el Espíritu parece ser el otro gran ausente (además del Padre): el Amor entre el Padre y el Hijo, de por sí efusivo y extático, está misteriosamente presente precisamente en la kénosis de la relación entre ellos. Y si es verdadero, tal y como se acaba de afirmar, que la especificidad del amor es precisamente la de hacerse presente en el desplazamiento de la atención desde sí mismo hacia los demás; en el evento del Gólgota, no podía manifestarse de un modo más visible, como Amor que une y distingue. Efectivamente la crucifixión es el lugar en el que el Hijo se diferencia radicalmente del Padre, por cuanto asume aquello que a Éste le resulta más extraño: Pablo dirá que Jesús se ha hecho "pecado" y "maldición” (cf. Gál 3,13 y 2Cor 5,21). Nunca como en la cruz se manifiesta una distinción tan grande entre Padre e Hijo. En realidad, esta dramática y aparentemente irreconciliable diversidad es el signo de la absoluta cercanía entre Ellos: y es el mismo Espíritu Santo, el Amor que une distinguiendo, entregado posteriormente a la humanidad "sin medida" (ésta es la clave de su presencia) ${ }^{18}$.

Lo que diferencia, por tanto, a las Tres personas divinas es el amor objetivo: el Padre no se reserva a su Hijo, el Hijo no se reserva a sí mismo, y el amor ofrecido, que los distingue a los Dos, es el Espíritu Santo, que, o bien expresa la distinción, o bien, por el contrario, siendo el mismo entre ambos, expresa su absoluta cercanía. La donación de sí se convierte en el motivo, ya de la distinción entre las tres divinas Personas, ya de su ser-uno.

Cuanto hemos puesto de relieve sobre el evento pascual y sobre la investigación llevada a cabo en torno a una posible comprensión de dicho evento, no se afirma a partir de una pregunta teórica-aunque

18 En los Evangelios, el don del Espíritu de Jesús ha sido expresado de maneras diversas: para expresar un simple hecho fisiológico, el Evangelio de Marcos usa el verbo "expiró", "exepneusen" (Mc 15,37), Mateo, "exhaló el espíritu”, "aphêken to pneuma" (Mt 27,50), y Lucas "entrego mi espíritu”, "paratithemai to pneuma" (Lc 23,46); en el Evangelio de Juan, sin embargo, Jesús "entregó el Espiritu”, "paredôken to pneuma" (Jn 19,30), el mismo verbo que es utilizado para expresar la entrega que el Padre hace del Hijo y que el Hijo hace de sí mismo. En estas tres afirmaciones vemos una connotación humana y una divina del Espíritu, por cuanto significan que precisamente en la entrega que Jesús hace de su espíritu humano, acontece la entrega, el don del Espíritu Santo. 
esté dotado de una audacia especulativa innegable-sobre si la logica crucis tiene todavia algo que enseñar; sino que es la propia época en la que se vive la que debe plantearse una seria reformulación sobre qué es lo negativo que, de hecho, ha entrado a formar parte del tejido sociocultural, político y eclesial. El "no", aquello que, en un cierto modo, asume la forma de lo totalmente otro respecto al ser, se ha incorporado también en el ámbito de las relaciones humanas. Desde esta perspectiva, el evento pascual de Jesús crucificado y resucitado, comprendido en su significado relativo, y no sólo salvador, revela el sentido último de aquel "no" relacional".

\section{UN PENSAMIENTO IN-FORMADO POR LA LÓGICA TRINITARIA}

A la luz de esta lectura teológica, ¿cómo se puede pensar entonces el evento pascual? Este "cómo pensar" el evento no significa formular un concepto de lo sucedido en el Gólgota, antes bien persigue una inserción del intelecto mismo del hombre dentro de la logica crucis a la que nos hemos referido. Pero antes de desarrollar este discurso sobre el "pensar", es importante avanzar progresivamente, subrayando en qué consiste este "no" del que se está hablando, a la luz del misterio cristológico-trinitario. Para llevar a cabo esto, nos dejamos guiar ahora en la reflexión por algunas claves presentes en la teologia de Piero Coda, quien ofrece una importante y novedosa aportación sobre el tema.

Captando el significado del "no-ser" dentro del lenguaje cristológico y trinitario, Coda arranca de una fundamental y necesaria distinción terminológica y de contenidos entre el "no-ser relativo" y el "no-ser relacional" in divinis ${ }^{20}$. El "no-ser relativo", que aparece de forma evidente en numerosos autores del pasado, es mencionado para expresar la distinción de las tres Personas en la única esencia divina, por medio de la cual, cada Persona es, en

19 En este sentido, ha sido discutida hace poco una tesis de doctorado en la que es ilustrada científicamente la peculiaridad del "no", en el marco teológico y filosófico: cf. S. Mazzer, "Li amò sino alla fine». Per una fenomenologia teologica del non dell'amore. Percorsi storici e prospettive sistematiche, Tesi Pontificia Università Lateranense - Istituto Universitario Sophia, Roma - Loppiano 2013.

20 Cf. P. Coda, Dalla Trinità, cit., p. 567-573. 
su no-ser la otra: el Padre "no es" el Hijo y el Hijo "no es" el Padre. Este "no-ser" es relativo, y por lo tanto no posee un valor absoluto: afirmar que el Padre "no es" el Hijo significa afirmar al mismo tiempo la peculiaridad específica del ser-Padre del Padre respecto al Otro (que es Hijo). A partir de esta lógica, se pregunta Coda:

Este no ser relativo, ¿expresa sólo, de modo absoluto, la subsistencia distinta de cada uno de los Tres, o dice algo sobre su relación? En otros términos, ¿el no-ser relativo no abriría acaso a la intuición, fundada en el evento mismo de la revelación, de un no-ser relacional? ${ }^{21}$.

Si el no ser relativo está referido a la peculiaridad de cada Persona divina en su relación con las Otras, el no ser relacional expresa el ser de cada Persona divina desde el momento en que entra en relación con las Otras. Tal movimiento orientado en Dios es el que Cristo mismo ha revelado al hombre en el evento pascual, plena manifestación de la actuación trinitaria: se trata de un amor "formado" en la apropiación de sí en el ser todo expropiado con, para y en el Otro. El no-ser, negativo, en este horizonte de comprensión (puesto ya de relieve en la reflexión de Hegel), no es una alternativa al ser, ni siquiera es su negación, sino que es su motor interno, su mismo modus essendi: cada Persona se encuentra dentro del espacio relacional del no-ser, como total donación de sí misma a las Otras $^{22}$.

La comunión trinitaria no nace únicamente del Acto extático de cada Persona individual hacia las Otras, sino dentro de

${ }^{21}$ Ibid., p. 568.

22 En esta lógica, de este modo Chiara Lubich describe las dinámicas intratrinitarias: "Il Padre genera il Figlio per amore: uscendo del tutto, per così dire, da sé, si fa, in certo modo, "non essere" per amore; ma è proprio così che è Padre. Il Figlio, a sua volta, quale eco del Padre, torna per amore al Padre, si fa anch'egli, in certo modo, "non essere" per amore, e proprio così è, Figlio; lo Spirito Santo, che è il reciproco amore tra Padre e Figlio, il loro vincolo d'unità, si fa, anch'egli, in certo modo, "non essere" per amore, quel non essere, quel "vuoto d'amore", in cui Padre e Figlio si incontrano e sono uno: ma proprio così è, Spirito Santo. Se consideriamo il Figlio nel Padre, il Figlio lo dobbiamo pensare dunque nulla (nulla d'Amore) per poter pensare Dio-Uno. E se consideriamo il Padre nel Figlio, dobbiamo pensare il Padre nulla (nulla d'Amore) per poter pensare Dio-Uno" (C. Lubich, Spiritualità dell'unità e vita trinitaria. Lezione per la laurea "honoris causa" in teologia, in "Nuova Umanità", XXVI (2004), 151, pp. 11-20, aquí p. 15). 
aquel espacio relacional entre las tres divinas Personas, que es el no-ser, la nada de cada una para las Otras: de esta manera, la comunión es "trinitaria", no sólo porque acontezca entre Tres sujetos protagonistas cada uno de ellos de sus propias acciones, sino porque "trinitaria" es la forma misma de la comunión, por la cual, cada una es simultáneamente prot-agonista al tener a las Otras siempre como co-agonistas de la misma acción ${ }^{23}$. Por esto, la comunión trinitaria no puede ser entendida como la suma del acto comunional de cada una hacia la Otra, sino más bien como lo que se lleva a cabo efectivamente desde aquel espacio común (de no-ser recíproco) entre las Tres divinas Personas, que ha germinado en virtud de la acción misma de cada una de ellas. Escribe en este sentido Coda:

De Dios, a partir de la revelación, se puede y se debe decir que es Él y es Amor (Ágape); del Padre, del Hijo y del Espiritu Santo, ya que subsisten por lo tanto en el darse hasta el fin reciprocamente, se puede y debe decir que estos son sólo (ellos mismos) en cuanto no son (en sí, independientemente de los otros), sino que se entregan dando todo de Sí mismos, y de este modo se reciben de vuelta (cf. Jn 10, 17-19)24.

Una vez que se ha puesto de manifiesto este modo de interpretar en qué consiste el "no", a la luz del misterio cristológico-trinitario, es posible ahora detener la atención sobre el acto del conocer que brota del "no-ser relacional" del que se ha hablado.

Una objeción inicial que podría ser planteada, en este sentido, consiste en cuestionar la razón de detenerse sobre el acto del conocimiento (que es una acción interna del sujeto), puesto que el objetivo fundamental no es otro sino alcanzar la comprensión de aquel "no" que ha determinado todas las dinámicas antropológicas actuales. Y sin embargo, se trata en verdad de captar en el dinamismo del pensamiento la posibilidad de com-prender un objeto y de "vivirlo" (esto es, de asumirlo) como la superación de los limites intrínsecos del objeto mismo.

\footnotetext{
23 El término "co-agonistas" pretende indicar precisamente las acciones divinas en el evento pascual (Cf. P. Coda, Dalla Trinità, cit., p. 265-267).

24 Ibid., p. 571.
} 
El filósofo alemán Hegel, cuyo pensamiento no pretendo aquí profundizar, ha desarrollado un método propio para poner de relieve su logica crucis: desde la conceptualización de un evento, hasta la interpretación que dicha conceptualización puede proporcionar a la realidad circundante. Piero Coda muestra sin embargo otro procedimiento hermenéutico: desde la conceptualización de un evento, hasta un nuevo pensamiento, in-formado por la lógica que emerge de aquel, el cual puede ser en sí mismo clave interpretativa de la realidad. No se trata de adquirir nuevos contenidos o categorias conceptuales para interpretar el presente, sino de alcanzar, a partir del evento pascual, un "nuevo estilo de pensar": no nuevos conocimientos, sino una nueva dinámica para inteligir la realidad.

Un "no" entendido como dinámica relacional sugiere inmediatamente que el acto del pensar no puede colocarse sobre la intelección de lo singular, sino sobre una relacionalidad pensante. Para confirmar esto, Coda se refiere con frecuencia a una elocuente expresión de Hilario de Poitiers: "Nemo enim novit nisi invicem", "ninguno de hecho conoce sino en reciprocidad" 25 . El paso decisivo se puede ejecutar sólo cuando se comprende que no se trata ya de pensar únicamente "la reciprocidad", sino de "pensar en reciprocidad"; esta modalidad del pensamiento podría ser denominada "intelección perijorética": hablar y escuchar en el otro. En otras palabras: el otro, el tú (que dirian los dialógicos) no sólo ayuda a mi yo a expresarse, sino que mi "yo" hace que el "tú" exprese y se exprese en mí y yo en él.

Si es verdad cuanto se ha dicho acerca de la interpretación del pensamiento de Coda sobre el no-relacional trinitario -esto es, que la dimensión comunional en Dios no nace del acto de la Persona concreta hacia las otras, sino dentro de aquel espacio relacional intratrinitario que es el no-ser, o mejor, el ser-nada de cada Uno para el Otro-, entonces el acto cognoscitivo (si el pensar debe asumir la forma del objeto conocido) no debe ser fruto de la propia subjetividad. Éste no puede proceder ni siquiera de la subjetividad que brota del encuentro con el otro, sino más

25 Hilario de Poitiers, De Trinitate II, 11. 
bien de un conocer que nace dentro de un espacio comunitario, no impersonal (sino habitado por la presencia de Cristo en el Espíritu). Tal espacio ha sido creado gracias al no-ser de cada uno respecto al otro, o mejor, gracias a la pérdida (esto es, a la negación) que cada uno debe poner en acto en sí mismo a favor de un conocimiento perijorético.

De esta lógica se sigue que un diálogo verdadero y auténtico se lleva a cabo no sólo en la alternancia de palabra y silencio, sino a través de una dinámica en la que cada uno habla y calla en el otro. Desde el individual acto personal de palabra (momento extático) y silencio (momento kenótico) se crea aquel espacio particular (el no-ser) que genera la comunión, o sea, volviendo a la reflexión sobre el acto de conocer, un nuevo conocer, no ya de cada uno a través de sí, sino de cada uno con, para y en el otro. Aquí nace un nuevo estilo de pensar: no ya una especulación a partir de la conceptualización del evento pascual, sino un conocimiento comunitario, in-formado dentro de la lógica trinitaria, plenamente manifestada por Jesús en la Cruz.

Dicho tipo de intelección, que germina por el espacio comunional del no-ser relacional, es siempre un conocimiento personal abierto al otro, no como a alguien externo al propio yo, sino interior a mí mismo. Es una dinámica que refleja la vida trinitaria ${ }^{26}$. Precisamente por esto, aunque es un inteligir en sí mismo plural, en cuanto fundado en la reciprocidad, permanece individual, o mejor, trinitariamente uno.

${ }^{26}$ Giuseppe Zanghì ha expresado así tal dinámica divina: "Il Figlio vive al massimo il rapporto con il Padre ma non come con qualcuno a Lui esterno, come con un "altro", ma con qualcuno intimo a se stesso; nell'uscita da sé nell'Altro ma che è in Lui, il Figlio supera l'alterità come oggettivazione nell'unica Soggettività divina che è lo "spirare" dei Tre l'uno nell'altro. Si ha l'Uno. Che è solo, allora - Uno -, non per esclusione ma per inclusione, perché è pericoresi, comunione. Ma comunione, appunto, misurata dalla solitudine-pienezza dell'Uno: non appoggio ad altro (l'unità sarebbe negata), ma dono di sé all'altro secondo un'alterità che non è "fuori" ma intima a colui che si dà - e per questo, perché si dà, di quella intimità rovesciata che è l'altro" (G.M. Zanghì, Dio che è Amore. Trinità e vita in Cristo, Città Nuova, Roma 20043, pp. 99-100). 
Jesús crucificado y resucitado deviene por tanto no sólo el objeto material del pensamiento, sino además la luz misma del conocimiento $^{27}$.

La interpretación de lo negativo, del "no", presente y siempre exuberante en todas las esferas de las relaciones humanas, puede ser creíble y no caer en una banalidad circunstancial sólo si el estilo de pensar la negación asume una cierta "forma agápica". Es de este nuevo conocer del que puede emerger una respuesta a la crisis presente, y también a la cuestión de la "muerte de Dios". Hegel había intentado ya explicar qué significa esta expresión, esto es, la muerte del Dios metafísico, el de «la autoconservación, la autodeterminación y la autoafirmación" ${ }^{28}$; en otras palabras: lo divino abstracto ${ }^{29}$.

La muerte de Dios no es ausencia que se contrapone a presencia, sino la caída y el fracaso de la cristología humana que buscaba comprender un sentido partiendo de una reflexión pre-trinitaria. La muerte entonces se coloca, se auto-coloca como momento, entendido como hiato, diástasis entre cruz y resurrección. Esta nada hiática, sin embargo, llega a ser objetiva posibilidad y necesidad subjetiva de una nueva hermenéutica: siendo hiato,

27 Escribe Giuseppe Zanghì en este sentido: "Gesù abbandonato. L'Essere che si fa, per amore, non-essere, per fare il non-essere Essere. [...] Egli è [...] l'oggetto formale della conoscenza: non ciò che essa conosce, ma la luce nella quale avviene la conoscenza. L'apertura nella quale "incollare" l'occhio perché esso veda nella verità. L'apertura per la quale non solo guardare ma entrare nella verità" (G.M. Zanghì, Gesù abbandonato maestro di pensiero, Città Nuova, Roma 2008, pp. 18-19).

28 E. Salmann, Il Logos con-diviso. Il cristianesimo come paesaggio aperto, in Presenza di spirito. Il cristianesimo come gesto e pensiero, EMP, Padova 2000, pp. 77-138, aquí p. 125.

29 También Mühlen ha abordado el problema de la muerte de Dios en su obra, Die abendländische Seinsfrage als der Tod Gottes und der Aufgang einer neuen Gotteserfahrung, Paderborn 1968; tr. it. a cura di G. Zappalà, Problema dell'essere e "morte di Dio". Il problema occidentale dell'essere come Morte di Dio ed i primi albori di una nuova esperienza di Dio, Città Nuova, Roma 1969. Él vincula la cuestión de la muerte de Dios a una interpretación teo-ontológica de Dios, para la cual la ausencia de Dios en el contexto actual es la fase culminante de un proceso argumentativo sobre el ser que ha ignorado la dimensión del tú. A este respecto, escribe: "L'estrema e più importante conseguenza di questo problema dell'essere privato della dimensione del Tu è appunto la morte di Dio, Soggetto del valore di un Tu» (H. Mühlen, Problema dell'essere e "morte di Dio", cit., p. 9). 
constituirá una distancia diferenciada de interpretaciones. Una de las cuales entiende precisamente la diástasis como momento del entregarse, del donarse, pero también de lo irreprimible y lo esquivo: es una nada que en el ofrecerse permanece siempre otra cosa, nada (precisamente porque no pierde, en la alteridad, su pureza originaria) ${ }^{30}$.

\section{CONCLUSIONES Y PERSPECTIVAS}

El acento que, en esta investigación, se ha colocado sobre lo negativo, sobre el "no" como modo mismo del ser (y no como su simple negación o contradicción) en su relacionarse intrínseco con el otro, ha señalado un cambio radical en la interpretación de todo lo que es. El pasaje de un ser in se que se auto-construye y se autorealiza a uno que es desde el momento en que se desplaza el propio baricentro existencial del in se al "para" y "en" el otro, encuentra en el ritmo mismo del ser-Dios de Dios su condición de posibilidad: tal dinámica es expresada a través de la palabra "ágape".

Una comprensión tal del ser, que marca tanto el abandono de una lógica sustancialista pre-personal, como una relectura del tema de la sustancia a la luz de la relación, no significa una simple aproximación, cargada de novedad, a la ontología, sino, tal y como se ha explicado, un nuevo horizonte de comprensión de la realidad. Comprensión que se puede poner en acto en el momento en el que la intelección misma es con-formada e in-formada por la dinámica agápica del ser: se trata, en otras palabras, no de un concepto abstracto, sino de una verdadera, auténtica y radical adhesión existencial al darse mismo del ser a aquello que le es irreduciblemente distinto de sí. Decía Klaus Hammerle a propósito de la ontología trinitaria: "pensarla significa entrar en su ritmo con el pensamiento, con la palabra, pero también con la existencia misma $\|^{31}$.

30 «Nel mistero della croce, Dio stesso scandaglia, percorre l'abisso, lo iato che corre fra lui e noi, fra grazia e peccato, fra creazione e storia, fra me e te, oggetto e soggetto, fra i diversi messianismi" (E. Salmann, Conoscenza - sapienza - teologia oggi, in Presenza di spirito, cit., pp. 53-76, aquí p. 68).

31 K. Hemmerle, Tesi di ontologia trinitaria, cit., p. 75. 
No es suficiente, en este sentido, un esfuerzo personal de adhesión o de inserción del propio dinamismo existencial dentro de un proceso relacional agápico: si fuera así, se trataría aun de una ontología trinitaria intra-personal (que busca la imagen de la Trinidad en la interioridad del sujeto), y no inter-personal. El mismo discurso puede ser utilizado para la unidad diferenciada de las diversas ramas de la teologia dentro de nuestras estructuras académicas. Para permanecer fieles al horizonte del que se ha hablado, no se trata ya de establecer cada disciplina teológica de forma que cada una de ellas pueda abordar, desde su propio punto de vista, el argumento de la relación y de la reciprocidad, para releer el tema propio a la luz de estas categorias (como si la Trinidad fuera el universal "objeto formal" de cada tratado). Se trata, por el contrario, de garantizar que cada disciplina teológica redescubra la propia especificidad en la salida de sí misma (dinámica exodal de la teología) para entrar en un diálogo real, honesto y fecundo con las demás (para reencontrarse en ellas); de modo que la pluralidad uniformada de los tratados teológicos podría recuperar su unidad originaria. Así, las realidades académicas podrían recomprenderse como "comunidades pensantes" y "espacios de reflexión en reciprocidad", no donde hacer realidad la verdad (cosa que podría resultar peligrosa), sino donde la verdad misma pueda "acontecer".

Es importante reiterar lo que ha sido subrayado desde la introducción misma de esta investigación: para que la ontología trinitaria sea tal, es necesario que no se proponga a sí misma como un sistema cerrado y exclusivo, con lenguaje y método propios, pretendiendo encontrar en sí la respuesta definitiva a las grandes cuestiones teológicas y filosóficas; ya que, de ese modo, terminaría convertida en un enrevesado intento de reducir a sí misma lo que es radicalmente diverso de ella.

Esta reflexión halla su fundamento argumentativo no sólo en la humilde posición que tendrá que caracterizar cada reflexión teológica (y de ello son maestros los grandes Padres de la Iglesia), sino además en la lógica interna de la misma ontología trinitaria, ya que ésta es y permanece siempre trinitarizante. 